\title{
Uma abordagem histórica sobre a interação da radiação com a matéria
}

\section{A historical description to the interaction of radiation with matter}

\section{RESUMO}

Este artigo apresenta uma revisão histórica das concepções sobre a natureza da luz, da ampliação do espectro solar para além da região do visível, da origem da teoria dos quanta e da interação da radiação com a matéria.

Palavras-chave: Natureza da luz; Espectro eletromagnético; Fótons; Teoria dos quanta; Radiação.

\begin{abstract}
This paper presents a historical review of the conceptions of the nature of light, the expansion of the solar spectrum beyond the visible region, the origin of quanta theory, and the interaction of radiation with matter.
\end{abstract}

Keywords: Nature of light; electromagnetic spectrum; photons; quantum theory; radiation.

\section{NATUREZA DA RADIAÇÃO}

A controvérsia entre as teorias corpuscular e ondulatória da luz surgiu entre os filósofos gregos, alguns dos quais acreditavam que a luz consistia em partículas que se moviam rapidamente e que eram emitidas pelos corpos luminosos em todas as direções, ao passo que outros a julgavam como um distúrbio num meio hipotético e inatingível. Até os últimos anos do século XVII não houve nenhum progresso científico real.

Em 1690 no seu "Tratado da Luz", Christiaan Huygens propôs que a luz consiste num movimento da matéria que se encontra entre nós e o corpo luminoso. Huygens explica que a luz é análoga ao som e se propaga num éter necessariamente material, uma vez que põe em movimento outras substâncias materiais. Argumenta que este éter não é lançado como uma bola (Figura 2), é a sede de verdadeiros movimentos vibratórios. Por meio da hipótese das ondulações (vibrações), demonstra as leis da reflexão, da refração e da refração dupla.

\footnotetext{
${ }^{1}$ IFSul - Instituto Federal de Educação, Ciência e Tecnologia do Sul-rio-grandense, Pelotas/RS - Brasil. Programa de Pós-Graduação em Ensino de Ciências e Tecnologias na Educação.

2 UFN - Universidade Franciscana, Santa Maria/RS - Brasil. Programa de Pós-Graduação em Ensino de Ciências e Matemática.
} 
Figura 1: Capa do Tratado da Luz de Christiaan Huygens.

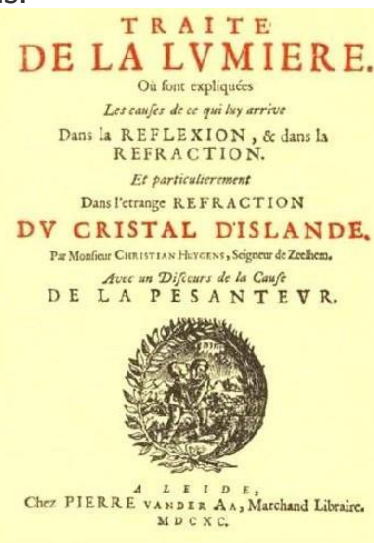

Figura 2: Modelo de propagação da luz proposto por Huygens. A bola $A$, em contato com diversas bolas idênticas CCC, é atingida por uma outra bola B. A bola A comunica o movimento às bolas CCC e, em seguida, as bolas A e B permanecem imóveis.

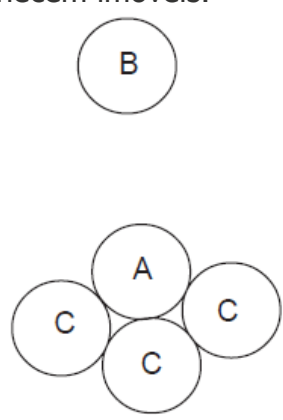

Como a Luz para Huygens era um movimento ondulatório, o desvio sofrido pela luz ao mudar de meio de propagação dependia da sua velocidade e como consequência o índice de refração seria maior quanto menor fosse a velocidade que a luz possuía ao penetrar no meio. Argumentava que se a luz fosse partícula, ocorreria o contrário. Em 1672, Newton apresentou à Royal Society uma comunicação considerando a luz uma realidade substancial e atribui-Ihe estrutura corpuscular. Ele propôs que as cores são qualidades da luz e é preciso que esta seja uma substância e não uma qualidade. Newton acreditava que se a luz fosse um fenômeno ondulatório, deveria se curvar ao redor de uma aresta, como faz o som. Ao contrário de Huygens, Newton acreditava que o meio mais denso aumentava a velocidade da luz.

Figura 3: Capa da segunda edição em inglês do Óptica.

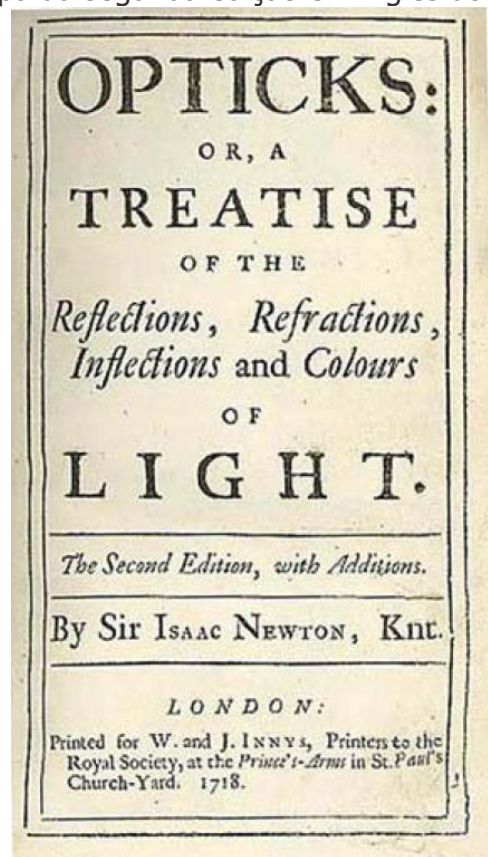

Newton debateu ambos os lados da questão, mas as partes dos seus escritos que favoreciam a teoria corpuscular impressionaram outros cientistas e, por mais de um século, sua exatidão não foi seriamente questionada. Nos meios cultos, nas universidades e nas escolas, a teoria corpuscular de Newton era oficialmente aceita.

O reflorescimento das teorias ondulatórias ocorreu na primeira metade do século XIX, com os trabalhos de Thomas Young e Augustin Fresnel. Em 1801, Thomas Young, retomando o estudo das franjas suscitadas pelas lâminas delgadas, anuncia o princípio das interferências luminosa, que teve 
por consequência a aceitação da teoria ondulatória. Por volta de 1820, Augustin Fresnel, sem conhecer o trabalho de Young, deduz os efeitos decorrentes de uma teoria ondulatória da luz, a partir de umas poucas hipóteses fundamentais: as vibrações de luz são senoidais, a difração se deve a superposição de ondas provenientes das extremidades da fenda (o que é incorreto) e há interferência da luz, conforme seu estado vibratório: em fase ou em oposição de fase. Foucault verificou em 1850 a previsão da teoria ondulatória de que a velocidade da luz na água é menor do que no ar. Este fato experimental, previsto na teoria ondulatória, e, em contradição com a teoria corpuscular, fez com que a teoria ondulatória fosse aceita unicamente.

Restava um ponto fraco: o éter. Para se explicar a propagação da luz no vácuo tinha se imaginado a existência de um meio que preencheria todo o espaço. Esse meio seria o propagador das ondas luminosas. As propriedades físicas desse meio deveriam, porém, ser tão contraditórias, que se tornava cada vez mais difícil defender a sua existência.

Ainda no século XIX, Maxwell mostrou a conexão entre luz e eletricidade, incluindo a hipótese ondulatória numa teoria eletromagnética da radiação, que foi aceita universalmente. Ele deduziu que as perturbações elétricas e magnéticas podiam propagar-se através do espaço na forma de um movimento ondulatório, com uma velocidade igual à da luz.

A carta enviada por Maxwell para Michelson, onde descrevia a dificuldade em se medir a velocidade da terra em relação ao éter, levou Michelson em 1881 (repetido juntamente com Morley em 1887) a construir um aparato para investigar a influência do "éter luminoso" sobre a velocidade da luz. Esse experimento, que ficou conhecido como experimento de Michelson-Morley, deixou clara e inexistência de um meio especial para a propagação da luz, ou seja, eliminaram de vez com o a ideia da existência do éter.

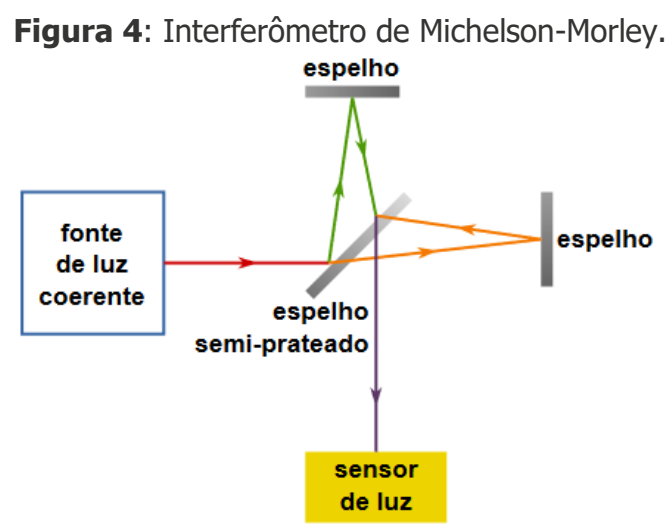

\section{CONCEPÇÕES ELETROMAGNÉTICAS DA RADIAÇÃO}

A concepção física da natureza vibratória da luz introduzida por Maxwell em 1865 ao ampliar as ideias de Faraday, mostrou que as perturbações elétricas e magnéticas poderiam propagar-se através do espaço na forma de movimento ondulatório, com uma velocidade igual a da luz. Hertz, em 1888, descobriu o que nós chamamos hoje de ondas de rádio, mostrando que elas obedecem às leis da reflexão e refração como ondas de luz.

A importante demonstração de que uma carga elétrica acelerada emitia ondas eletromagnéticas foi realizada, em 1897, pelo físico e matemático inglês Sir Joseph Larmor (1857-1942), o qual 
apresentou sua expressão para o cálculo da potência irradiada por partículas carregadas e a sua demonstração permitiu explicar, por exemplo, a radiação térmica, que passou a ser analisada como o resultado da aceleração das cargas elétricas nas proximidades da superfície de um corpo em processo de agitação térmica.

Se analisarmos um feixe de luz plana e polarizada propagando-se no vácuo, constataremos a presença de campos magnéticos e elétricos variáveis, que se deslocam com a velocidade da luz. Observa-se que no vácuo o campo magnético não está associado a nenhum imã ou corrente elétrica, bem como o campo elétrico tem carga que o acompanhe. Efetivamente esses campos têm suas origens nas oscilações de algum sistema de cargas elétricas, mas, uma vez a radiação tenha se afastado da fonte, passa a ser uma entidade independente e livre das cargas elétricas que a produziram.

No caso de uma luz polarizada monocromática, propagam-se juntas e em fase uma onda magnética simples e uma onda elétrica simples. Ainda que os planos da perturbação magnética $\mathrm{H}$ seja normal ao da perturbação elétrica $\mathrm{E}$, os máximos e mínimos de uma coincidem com o da outra. Ambas possuem a mesma frequência e o mesmo comprimento de onda. Entretanto, verifica-se em geral que as radiações produzidas por fontes reais são inteiramente complexas. O conjunto complexo pode ser considerado como uma superposição de muitas ondas simples, as quais diferem no comprimento de onda e na frequência.

\section{ESPECTRO ELETROMAGNÉTICO}

Willian Herschel, em 1800, mostrou que o espectro solar se estendia por comprimentos de onda maiores que os do vermelho visível, mas a pesquisa não avançou por falta de instrumentos adequados. Herschel fez a "luz solar" atravessar um prisma de modo a formar um arco-íris (espectro visível). Ele estava interessado na medida da quantidade de calor associada a cada cor e para fazer isto ele usou termômetros com bulbos cobertos de preto, medindo a temperatura nas diferentes cores do espectro. Percebeu que a temperatura crescia da parte azul do espectro para a parte vermelha e então, posicionou o termômetro um pouco além da parte vermelha do espectro, em uma região aonde não havia incidência de luz visível e verificou que a temperatura que o termômetro media era mesmo mais alta. Ele concluiu então que deveria haver "outro tipo de luz" o qual não podia ser visto nesta região. Esta luz ele chamou de infravermelho.

Figura 5: Aparato utilizado por Herschel para investigar o poder de aquecer e iluminar das diferentes cores prismáticas.

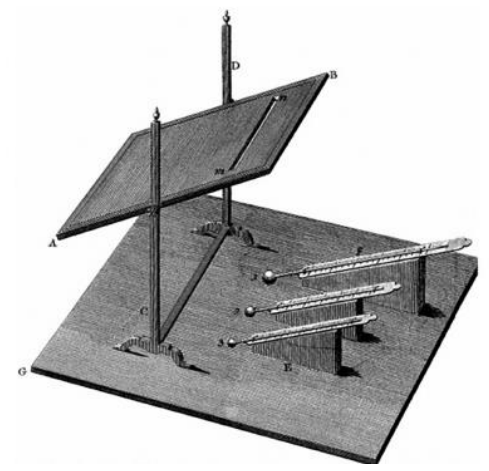

Fonte: http://www.scielo.br/pdf/rbef/v36n4/v36n4a22.pdf 
A extensão do espectro para além do violeta foi proposto por Johann Ritter em 1801. Ele estava trabalhando com cloreto de prata, que se torna escuro quando exposto a luz e tinha conhecimento que a luz azul produzia um efeito maior no cloreto de prata que a luz vermelha. A partir daí, procurou montar um aparato experimental para tentar medir a taxa com que o cloreto de prata reagia com as diferentes cores do espectro visível. Direcionando a luz solar de modo que atravessasse um prisma para criar o espectro, colocou cloreto de prata sob cada cor do espectro e encontrou que era possível observar uma pequena mudança na parte vermelha do espectro, escurecendo em direção a região violeta do espectro. Decidiu então colocar a cloreto de prata um pouco além da luz violeta visível do espectro, em uma região aonde não incidia visivelmente a luz solar e observou uma reação mais intensa. Isto mostrou pela primeira vez que luz existia para além do violeta. Este "novo tipo" de luz, que ele chamou de raios químicos, foi mais tarde renomeado como luz ultravioleta. George Gabriel Stokes, em 1852, investigou a luz ultravioleta usando lentes e prisma de quartzo, identificado suas raias por meio de telas fluorescentes.

Figura 5: Experimento de Ritter.

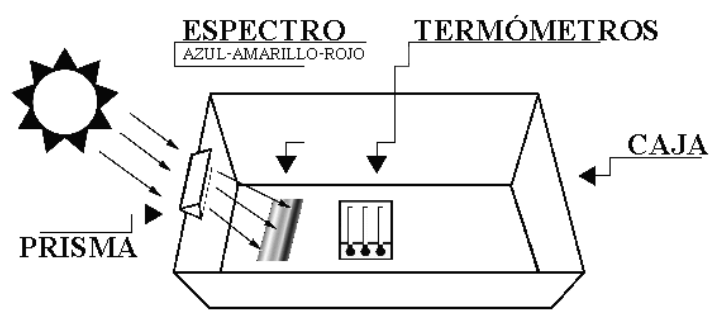

Fonte: http://www.if.ufrgs.br/ riffel/notas_aula/ensino_astro/roteiros/Roteiro_Experimento_Ritter.htm

A Tabela 1 mostra o espectro eletromagnético e os nomes associados com os vários intervalos de frequência e comprimentos de onda. O olho humano é sensível à radiação eletromagnética com comprimentos de onda entre 400nm e 780nm, que é chamada luz visível. Os menores comprimentos de onda da luz visível são os da luz ultravioleta e os mais longos são os da luz vermelha.

Tabela 1 - Separação do espectro eletromagnético em faixas.

\begin{tabular}{|c|c|c|c|}
\hline $\begin{array}{l}\text { Radiação } \\
\text { eletromagnética }\end{array}$ & Frequência & $\begin{array}{l}\text { Comprimento } \\
\text { de onda }\end{array}$ & $\begin{array}{l}\text { Energia do fóton } \\
(\mathrm{eV})\end{array}$ \\
\hline raios $X$ e gama & $>3 \mathrm{PHz}$ & $<100 \mathrm{~nm}$ & $>12$ \\
\hline Ultravioleta UVC & $3 \mathrm{PHz}-1,07 \mathrm{PHz}$ & $100 \mathrm{~nm}-280 \mathrm{~nm}$ & $12,42-4,42$ \\
\hline UVB & 1,07 PHz - 0,952 PHz & $280 n m-315 n m$ & $4,42-3,94$ \\
\hline UVA & $0,952 \mathrm{PHz}-0,75 \mathrm{PHz}$ & $315 n m-400 n m$ & $3,94-3,10$ \\
\hline luz visível & $0,75 \mathrm{PHz}-0,428 \mathrm{PHz}$ & $400 n m-700 n m$ & $3,10-1,77$ \\
\hline Infravermelha IVA & $385 \mathrm{THz}-214 \mathrm{THz}$ & $780 \mathrm{~nm}-1,4 \mu \mathrm{m}$ & $1,59-0,88$ \\
\hline IVB & $214 \mathrm{THz}-100 \mathrm{THz}$ & $1,4 \mu \mathrm{m}-3,0 \mu \mathrm{m}$ & $0,88-0,414$ \\
\hline IVC & $100 \mathrm{THz}-300 \mathrm{GHz}$ & $3,0 \mu \mathrm{m}-1,0 \mathrm{~mm}$ & $0,414-1,24 \times 10^{-3}$ \\
\hline $\begin{array}{l}\text { radiofrequência } \\
\text { micro-onda }\end{array}$ & $\begin{array}{c}300 \mathrm{GHz}-10 \mathrm{kHz} \\
300 \mathrm{GHz}-300 \mathrm{MHz}\end{array}$ & $\begin{array}{c}1 \mathrm{~mm}-30 \mathrm{~km} \\
1 \mathrm{~mm}-1 \mathrm{~m}\end{array}$ & muito pequena \\
\hline $\begin{array}{l}\text { frequência extrema- } \\
\text { mente baixa }\end{array}$ & $300 \mathrm{~Hz}-0 \mathrm{~Hz}$ & $10^{6} \mathrm{~m}-\rightarrow \infty$ & $\begin{array}{l}\text { extremamente } \\
\text { pequena }\end{array}$ \\
\hline
\end{tabular}

$K($ quilo $)=10^{3} ; M($ mega $)=10^{6} ; G($ giga $)=10^{9} ; T($ tera $)=10^{12} ; P($ peta $)=10^{15}$ 
As ondas de rádio, a radiação infravermelha, a radiação visível, a radiação ultravioleta e os raios $X$, têm suas origens fora do núcleo atômico, enquanto os raios gamas têm origem no núcleo, através da desintegração radioativa.

\section{ORIGEM DA TEORIA DOS QUANTA (FÓTONS)}

Um problema espinhoso que a Física não conseguia resolver era a radiação emitida por um corpo negro. As teorias clássicas, que se baseavam nos princípios da Termodinâmica e nas leis do Eletromagnetismo não conseguiam explicar a forma do seu espectro de emissão. A solução foi proposta em uma audaciosa hipótese, em 1900, pelo físico alemão Max Planck, que apresentou à Sociedade Alemã de Física, um estudo teórico sobre a emissão de radiação de um corpo negro, no qual deduz uma equação plenamente em acordo com os resultados experimentais. Entretanto, para conseguir essa equação, teve que considerar a existência, na superfície do corpo negro, de cargas elétricas oscilantes emitindo energia radiante não de modo contínuo, como sugere a teoria clássica, mas sim em porções descontínuas, "partículas" que transportam, cada qual, uma quantidade de energia $E$ bem definida de energia.

Ele sugeriu a hipótese de que a energia $E$ de uma onda eletromagnética de frequência $f$ (medida de hertz) não pode ter um valor qualquer, mas apenas múltiplos inteiros de uma energia mínima. Essa energia mínima é $E=h f$, onde $h$ é uma constante, cujo valor foi determinado por Planck de modo que sua teoria explicasse os resultados experimentais conhecidos. A essa quantidade mínima de energia que uma onda eletromagnética de determinada frequência pode transportar, chamou-se de quantum de luz.

A ideia de Planck foi retomada e ampliada por Einstein, em 1905, ao explicar o efeito fotoelétrico que foi observado por Hertz e publicado em junho de 1887. Hertz descobria, na época supracitada, um novo laço entre a óptica e a eletricidade, cuja importância teórica e prática iria crescer incessantemente: a influência da luz ultravioleta sobre a descarga elétrica. Ele verificou que, sob condições idênticas, uma faísca elétrica saltaria a uma distância maior de um eletrodo negativo limpo e carregado quando iluminada por luz ultravioleta. Esse trabalho foi corroborado por Hallwachs, em 1888, que verificou que uma placa de zinco, não carregada e isolada, exposta à luz ultravioleta de um arco de carvão, adquiria carga positiva, como era indicado por um eletroscópio de folhas de ouro. As observações de Hertz e Hallwachs ocorreram antes do isolamento do elétron, da identificação de sua carga e de qualquer teoria que explicasse a ionização por choque para guiar os investigadores na interpretação do mecanismo de produção de uma faísca elétrica.

Figura 6: Experimento de Hallwachs.

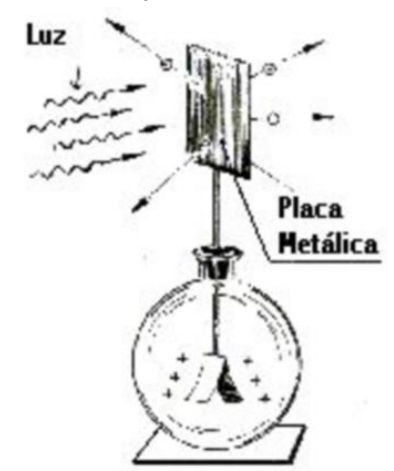

Fonte: https://www.researchgate.net/figure/Figura-1-Experimento-de-Hertz-Hallwachs_fig1_304827132 
O efeito fotoelétrico consiste na retirada de elétrons da superfície de um metal atingido por radiação eletromagnética. A interpretação de Einstein para esse efeito permitiu confirmar o valor da constante $h$, conhecida como constante de Planck: $h=6,626 \times 10^{-34} \mathrm{~J} \times s$. Observe que o valor de $\mathrm{h}$ é muito pequeno e isso significa que cada quantum do campo eletromagnético transporta uma quantidade de energia muito pequena. Os quanta se propagam no vácuo como um corpúsculo sem massa com velocidade $c$. Os quanta do campo eletromagnético são também chamados de fótons.

Volta-se, assim, de certa maneira, à teoria corpuscular. Apenas os corpúsculos seriam energia e não materiais. Mas para explicar os fenômenos nitidamente ondulatórios como a interferência, a difração e a polarização, era preciso associar a cada fóton uma certa frequência de vibração. Então, os fótons possuem propriedades semelhantes às de uma onda, pois apresentam uma frequência $f$ bem definida. Por outro lado, possuem propriedades semelhante às de um corpúsculo. Isso mostra a natureza complexa das radiações eletromagnéticas que podem se comportar ora como onda e ora como partícula.

Foi Louis de Broglie, em 1924, em sua tese de doutorado, quem sugeriu esta natureza dual da luz: os fótons se comportam ora como onda (quando se propagam no espaço) e ora como partícula (quando emitidos e absorvidos). Essa dualidade onda-partícula fica melhor compreendida pelo princípio da complementaridade, proposto por Niels Bohr em 1928, que explica como os aspectos de partícula e de onda complementam um ao outro. Ambos são necessários, mas não podem ser observados ao mesmo tempo. A observação de um ou outro aspecto depende do arranjo experimental.

\section{CARACTERÍSTICAS DE CADA FAIXA ESPECTRAL E A SUA INTERAÇÃo COM A MATÉRIA}

\section{i. Ondas de Rádio}

São radiações com frequência menor que $300 \mathrm{MHz}$, com comprimentos de onda superiores a 0,3 m e com energia extremamente pequena (inferior a $10^{-5} \mathrm{eV}$ ). São geradas por circuitos oscilantes, em transmissores de estações, mas também em grandes corpos no espaço, tais como cometas, planetas ou nuvens de gás gigantes. São ondas utilizadas principalmente em telecomunicações e radiodifusão (rádio, TV e telefones celulares). No nível atômico e molecular, as ondas de rádio não provocam efeitos sobre a matéria; o corpo humano, como a maioria dos materiais, é transparente a essas radiações.

As ondas de rádio, cujas frequências estão compreendidas entre $10^{4} \mathrm{~Hz}$ e $10^{7} \mathrm{~Hz}$ (comprimentos de onda variando entre $10 \mathrm{~km}$ a $10 \mathrm{~m}$ ), podem ser captadas a milhares de quilômetros, pois se refletem nas camadas ionizadas da atmosfera. Já os sinais de TV com frequências mais altas, na ordem de $10^{8} \mathrm{~Hz}$ (comprimento de onda de aproximadamente $1 \mathrm{~m}$ ), são irradiadas paralelamente ao solo e por isso, bloqueadas por obstáculos de pequenas dimensões.

\section{ii. Micro-ondas}

São radiações eletromagnéticas produzidas por sistemas eletrônicos (osciladores) e se estendem pela região do espectro de $1 \mathrm{~mm}$ até cerca de $1 \mathrm{~m}$, o que corresponde ao intervalo de frequência de $300 \mathrm{GHz}$ a $300 \mathrm{MHz}$ e possuem energias muito pequena $\left(10^{-5} \mathrm{a} 10^{-3} \mathrm{eV}\right)$. 
As micro-ondas estão no intervalo de energias separando os estados quânticos de rotações e torções moleculares. A interação dessas ondas com materiais diferentes dos condutores metálicos fará rodar as moléculas e produzir calor como resultado daqueles movimentos moleculares. Os condutores absorvem fortemente as micro-ondas e frequências mais baixas. Ao serem absorvidas, essas frequências causam correntes elétricas que aquecem o material. A maioria dos materiais, incluindo o corpo humano, é largamente transparente às micro-ondas. Micro-ondas de altas intensidades, como num forno de micro-ondas, produzem milhares de vibrações nas moléculas de água dos alimentos, aquecendo o alimento por produzir rotações e torções moleculares. Não produzem ionização.

As micro-ondas são usadas na pesquisa para se obter informações sobre a estrutura de moléculas. São também usadas para a transmissão de informações como em radares, sensoriamento remoto e, ainda, em telefonia celular e transmissão de dados informatizados. Como as micro-ondas conseguem atravessar a ionosfera, são usadas nas comunicações via satélite.

\section{iii. Infravermelho}

São as radiações eletromagnéticas de comprimento de onda variando entre $1,0 \mathrm{~nm}$ a $780 \mathrm{~nm}$. A energia dos seus fótons está no intervalo de $1,24 \times 10^{-3} \mathrm{eV}$ a $1,59 \mathrm{eV}$ que é o intervalo de energia dos estados quânticos das vibrações moleculares. O infravermelho é absorvido com facilidade pela maioria dos materiais, resultando no aumento da atividade vibracional das moléculas.

O infravermelho curto $(0,8-1,5 \mu \mathrm{m})$ pode penetrar na porção profunda da pele sem causar aumento marcante na temperatura da superfície do epitélio, enquanto os infravermelho médio e longo (1,5$1.000 \mu \mathrm{m}$ ) ao ser absorvido pela camada superior da pele, produz com frequência efeitos térmicos danosos, como queimaduras ou a sensação de queimação, mas pode promover regeneração celular.

A radiação infravermelha é usada em controles remotos, leitores de códigos de barras, mouses de computador. Câmeras sensíveis ao infravermelho (com menor comprimento de onda) conseguem mostrar as áreas mais quentes dos corpos, que ficam nas cores amarelo e laranja (não correspondem as cores naturais). Receberam esta nomenclatura, pois elas têm frequência abaixo da correspondente à cor vermelha e é uma radiação não ionizante.

\section{iv. Visível}

Refere-se à parte do espectro com comprimento de onda entre $40 \mathrm{~nm}$ e $700 \mathrm{~nm}$ (frequências entre aproximadamente $4,3 \cdot 10^{14}$ a $7,5.10^{14} \mathrm{~Hz}$ ), que o olho humano consegue detectar. A origem da luz está nas oscilações ou transições dos elétrons entre as camadas mais externas dos átomos.

Possuem energia entre 1,77 eV e 3, $10 \mathrm{eV}$, tendo como principal mecanismo para a absorção de fótons, a elevação dos elétrons a níveis de energia mais altos. Existem muitos estados disponíveis, assim a luz visível é absorvida fortemente. A exposição à luz visível causa aquecimento e não produz ionização.

\section{v. Ultravioleta (UV)}

A radiação ultravioleta possui comprimentos de onda entre $100 \mathrm{~nm}$ e $400 \mathrm{~nm}$, frequências entre 0,75 $\mathrm{PHz}$ e $3 \mathrm{PHz}$ e energia de 3,10 a 12,42 eV. Tais radiações têm a propriedade de favorecer certas 
reações químicas, como, por exemplo, as que formam ozônio nas camadas mais altas da atmosfera e as que produzem melanina, pigmento de escurece a pele.

Nesta faixa de energia está o limiar entre as radiações não-ionizantes e as ionizantes. Dado às altas energias que carregam, as radiações ultravioletas são fortemente absorvidas pela maioria das substâncias sólidas. Assim como a luz, as radiações ultravioletas também se originam de transições eletrônicas das camadas mais externas dos átomos.

As radiações ultravioletas de menores comprimentos de onda (principalmente o UVC) têm energia no patamar da energia de ionização de muitas moléculas, tornando-se assim muito perigosas, pois podem produzir danos à saúde, como por exemplo o câncer de pele. A camada de ozônio na atmosfera superior é importante para a saúde humana porque ela absorve a maioria da radiação ultravioleta (energias mais altas) prejudicial, oriunda do sol, antes dela atingir a superfície.

A maior fonte de radiação ultravioleta é o sol, porém, ela é produzida também por lâmpadas fluorescentes e de descarga de mercúrio, lasers, os arcos de solda elétrica, usados para soldar metais. Nossos olhos são particularmente suscetíveis aos danos das radiações ultravioletas, pois elas provocam a conhecida inflamação UV ou mesmo a cegueira e por esse motivo um soldador deve utilizar um visor de proteção. As lâmpadas que emitem UV são utilizadas em diversas áreas: germicida, cosmética, análise química, processos tecnológicos, forenses. Também é usada no tratamento de doenças, como: psoríase, eczemas, vitiligo, icterícia, etc.

\section{vi. Raios-X}

No dia 8 de novembro de 1895, Wilhelm Conrad Röntgen, então professor de física na Universidade de Würzburg, Bavária, Alemanha, descobre uma nova espécie de radiação produzida pela passagem de uma corrente elétrica por um tubo de vidro sob vácuo (tubo de Crooke), e que possuía a singular qualidade de, embora invisível a olho nu, produzir fluorescência ao incidir sobre uma tela de platinocianeto de bário. Mais impressionante era a capacidade destes raios de atravessar corpos sólidos (madeira, papel, partes do corpo humano), com maior ou menor intensidade, dependendo da natureza do material.

Os raios $X$ possuem comprimentos de onda entre $0,01 \mathrm{~nm}$ e $1 \mathrm{~nm}$, frequências entre $3 \times 10^{16} \mathrm{~Hz}$ a $3 \times 10^{19} \mathrm{~Hz}$ e energia entre $100 \mathrm{eV}$ e $100 \mathrm{keV}$. Os raios $\mathrm{X}$ podem ser produzidos quando elétrons acelerados são bruscamente detidos por colisão com átomos metálicos. A maioria dos elétrons acelerados são absorvidos ou espalhados, produzindo aquecimento no alvo. Cerca de $5 \%$ dos elétrons sofrem reduções bruscas de velocidade, e a energia dissipada se converte em ondas eletromagnéticas, denominadas de raios $X$.

Os raios $X$ são classificados como radiação ionizante, pois a sua energia são muito altas para serem absorvidas nas transições eletrônicas. Os fótons de raios $X$ de alta energia podem criar um par elétronpósitron. Quanto menor o seu comprimento de onda (maior frequência), maior é o poder de penetração na matéria. Essa propriedade nos permite investigar estruturas que não estão aparentes.

O efeito fundamental dos raios $X$ sobre a matéria são a produção de elétrons de alta velocidade, em todas as partes do material que atravessam. Alguns desses são fóton elétrons, outros elétrons de recuo produzido por um fenômeno conhecido como efeito Compton. Compton mostrou que quando um feixe de raio $X$ incidia num alvo de grafite ( $a$ interação acontece entre 0 fóton incidente $e$ 
o elétron no material), ocorria que o raio $X$ era espalhado em duas partes: a parte não modificada mantendo o comprimento de onda original, e a parte modificada apresentando um comprimento de onda ligeiramente aumentado, correspondendo a uma energia menor. A ocorrência da primeira é explicável pela teoria clássica; a segunda requer que a radiação seja considerada como fótons semelhante a projéteis, ou seja, evidencia as propriedades corpusculares da luz.

Figura 7: A primeira de Wilhelm Röntgen referente a mão de sua esposa, tirada em 22 de dezembro de 1895 e apresentada ao Professor Ludwig Zehnder, do Instituto de Física da Universidade de Freiburg, em 1 de janeiro de 1896.

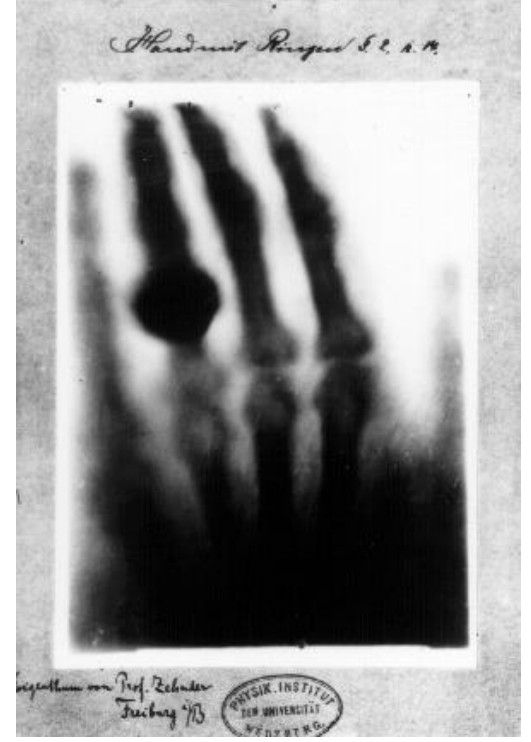

Fonte: https://www.timelinefy.com/view/event/91/234/3907/primeira-radiografia-registrada-raio-x/

\section{vii. Raios gama}

Os frequência dos raios y situa-se acima de $10^{19} \mathrm{~Hz}$, que implica comprimentos de onda abaixo de $10^{-12} \mathrm{~m}$ e energias acima de 0,1 MeV (a energia da radiação visível oscila entre 1 e 4 eV, cerca de 50 000 vezes menor) e são produzidos em processos de decaimento nuclear. Foram descobertos, em 1900, pelo físico francês Paul Villard quando estudava a radiação emitida por uma amostra de rádio. Rutherford foi quem efetivamente identificou essa radiação e percebeu que se tratava de um terceiro tipo, tendo em vista que já eram conhecidas as emissões $\alpha$ e $\beta$, decorrente do decaimento radioativo e designou-a, em 1903, por radiação Y.

A radiação y apresenta um elevado poder de penetração na matéria, comparado com as radiações $\alpha$ e $\beta$, e embora menor poder de ionização, é a mais perigosa para o ser humano. Enquanto as radiações a e $\beta$ são geralmente barradas pela pele, a radiação y consegue penetrar e, até atravessar o corpo, causando danos a nível celular, o que pode aumentar a incidência de câncer. O seu poder ionizante decorre de três tipos de interação que pode ter com a matéria: efeito fotoelétrico, efeito Compton e produção de um par elétron-pósitron. As radiações y com energias entre 3 e $10 \mathrm{MeV}$ são as mais perigosas a nível biológico, uma vez que o corpo é relativamente "transparente" à radiação $y$ de energia mais elevada.

A radiação y é utilizada para esterilizar equipamento médico e alimentos, no tratamento de certos tipos de câncer, em diagnósticos e também, utilizada em scanners de forma a detectarem o conteúdo de veículos de transporte de mercadorias (VACIS - Vehicle and Container Imaging System, um scanner de raios $Y$ ). 


\section{REFERÊNCIAS}

BLACKWOOD, O. H.; OSGOOD, T. H.; RUARH, A. E. Introdução a Física Atômica. Trad. Ruy Pinto da Silva Sieczkowski. Porto Alegre: Editora Globo, 1960.

Spencer Lima, L. (2014), Raios Gama. Revista de Ciência Elementar, 2(04):0110. Disponível em: https://www.fc.up.pt/pessoas/jfgomes/pdf/vol 2 num 4110 art radiacaoGama.pdf. $\quad$ Acesso: 02/05/2019.

MARTINS, Roberto de Andrade. O éter e a óptica dos corpos em movimento: a teoria de Fresnel e as tentativas de detecção do movimento da Terra, antes dos experimentos de Michelson e Morley (18181880). Caderno Brasileiro de Ensino de Física 29 (1): 52-80, 2012.

MARTINS, Roberto de Andrade. Becquerel e a descoberta da radioatividade: uma análise crítica. São Paulo: Livraria da Física, 2012.

MURANI, Orestes. Tratado de Física. Barcelona: Gustavo Gili, 1924.

NOBRE, Francisco Ribeiro. Tratado de Física Elementar. Porto: Livraria Lello \& Irmão, 1945.

OKUNO, Emico; YOSHIMURA, Elisabeth. Física das Radiações. São Paulo: Oficina de Textos, 2010.

RIFFEL, Rogério. 0 Experimento de Ritter. Disponível em: http://www.if.ufrgs.br/ riffel/notas aula/ensino astro/roteiros/Roteiro Experimento Ritter.htm. Acesso: 02/05/2019.

SCHURMANN, Paul. História de La Fisica. Tomo I, $2^{\circ}$ ed. Buenos Aires: Editorial Nova, 1945.

SCHURMANN, Paul. História de La Fisica. Tomo II, $2^{\circ}$ ed. Buenos Aires: Editorial Nova, 1945.

TATON René. A Ciência Moderna. Tomo II, n. 2. Trad. Geraldo Gerson de Souza. São Paulo: Difusão Europeia do Livro, 1960.

TATON René. A Ciência Moderna. Tomo II, n. 4. Trad. Geraldo Gerson de Souza. São Paulo: Difusão Europeia do Livro, 1960.

TATON René. A Ciência Moderna. Tomo III, n. 1. Trad. Geraldo Gerson de Souza. São Paulo: Difusão Europeia do Livro, 1960.

TATON René. A Ciência Moderna. Tomo III, n. 3. Trad. Geraldo Gerson de Souza. São Paulo: Difusão Europeia do Livro, 1960. 